\title{
Interactions involving intestinal nematodes of rodents: experimental and field studies
}

\author{
J. M. BEHNKE ${ }^{1 *}, \mathrm{~A} . \mathrm{BAJER}^{2}, \mathrm{E}_{\text {S SINSKI}}{ }^{2}$ and D. WAKELIN ${ }^{1}$ \\ ${ }^{1}$ School of Life and Environmental Sciences, University Park, University of Nottingham, Nottingham NG7 2RD, UK \\ ${ }^{2}$ Department of Parasitology, Institute of Zoology, University of Warszawa, ul.Krakowskie Przedmiescie 26/28, 00-927 \\ Warszawa, Poland
}

S U M M A R Y

Multiple species infections with parasitic helminths, including nematodes, are common in wild rodent populations. In this paper we first define different types of associations and review experimental evidence for different categories of interactions. We conclude that whilst laboratory experiments have demonstrated unequivocally that both synergistic and antagonistic interactions involving nematodes exist, field work utilizing wild rodents has generally led to the conclusion that interactions between nematode species play no, or at most a minor, role in shaping helminth component communities. Nevertheless, we emphasize that analysis of interactions between parasites in laboratory systems has been fruitful, has made a fundamental contribution to our understanding of the mechanisms underlying host-protective intestinal immune responses, and has provided a rationale for studies on polyparasitism in human beings and domestic animals. Finally, we consider the practical implications for transmission of zoonotic diseases to human communities and to their domestic animals, and we identify the questions that merit research priority.

Key words: Rodents, nematodes, helminths, associations, co-occurrence, synergistic interactions, antagonistic interactions, field studies, experimental studies.

\section{INTRODUCTION}

All animals are exposed, on a daily basis, to a wide range of infectious organisms. Consequently, it is rare for them to be uninfected or even to carry just a single species of pathogen. Most animals can act as hosts for a parasite fauna comprising a range of species, and surveys have consistently shown that in nature the majority of individuals carry more than one species concurrently. Wild rodents in the UK show a mean helminth species richness of 2 or more (Lewis 1968 $a, b$; Montgomery \& Montgomery, 1989; Behnke et al. 1999). This is a common finding in rodents elsewhere (Haukisalmi \& Henttonen, $1993 a$; Tenora \& Stanek, 1995) which extends to many other mammals (Pence, Crum \& Conti, 1983); Waid, Pence \& Warren, 1985), birds (Bush \& Holmes, 1986); Kennedy, Bush \& Aho, 1986), and even to human beings. In regions where human helminth infections are endemic, multiple species infection (polyparasitism) is common, rather than exceptional (Buck et al. 1978); Keusch \& Migasena 1982; Kvalsvig, 1988); Ashford, Craig \& Oppenheimer 1992); Chunge et al. 1995).

The component community structure of helminths in wild rodents in any geographical region is dynamic and known to be influenced by both extrinsic (year, season, site) and intrinsic (host sex, age, reproductive status) factors (Haukisalmi, Henttonen \& Tenora, 1988); Boggs et al. 1991); Abu-

* Corresponding author: Tel: 0115951 3208. Fax: 0115 951 321. E-mail: jerzy.behnke@nottingham.ac.uk
Madi et al. 1998, 2000); Behnke et al. 1999). These, and other factors, combine to shape the component community structure in ways that vary from location to location (Mollhagan, 1978); Martin \& Huffman, 1980; Montgomery \& Montgomery, 1989); AbuMadi et al. 1998). In general, extrinsic factors have a greater influence than intrinsic factors, but their precise individual and combined contributions have seldom been fully evaluated (e.g. seasonal influences may in part reflect seasonal changes in host reproductive hormone cycles and associated changes in immunocompetence). Perhaps the least understood factor in this context is the extent to which the component communities of helminths in rodents are shaped by interactions between the parasites themselves.

In this paper, focusing on rodent hosts, we review the evidence for interactions between parasites, in which at least one of the associates is an intestinal nematode. This paper therefore builds on the earlier review by Christensen et al. (1987) and, in the light of Petney \& Andrews (1998), addresses the specific issue of whether intestinal nematodes predispose their hosts to infections by heterologous species. First, we define different types of associations between species and review experimental evidence for different categories of interactions. Then we evaluate the evidence for interactions between species in wild rodent populations and whether experimental studies have improved our understanding of the role of interactions in the component community structures of helminths in wild rodent populations. We emphasize that analysis of inter- 
actions between parasites in laboratory systems has been a fruitful approach that has made a fundamental contribution to our understanding of the mechanisms underlying host-protective intestinal immune responses. Finally, we consider the practical implications for transmission of zoonotic diseases to human communities and to their domestic animals, and we identify the questions that merit research priority.

CATEGORIES OF INTERACTION

At its simplest level, co-occurrence of different species of parasites may reflect quite independent infection processes. For example, if infective stages of several parasites are aggregated in the environment, the individual hosts that frequent such sites will be more exposed to infection and as a result carry heavier mixed burdens than others. Infections are likely to accumulate with time and consequently, with increasing host age, parasite burdens may grow heavier and more diverse (mean helminth species richness is known to increase with host age in wood mice, Montgomery \& Montgomery, 1989), Behnke et al. 1999). Variations in host behaviour, in particular in exposure-related activities, are believed to be the principal determinants of predisposition to infection in humans (Bundy \& Blumenthal, 1990); Chan, Bundy \& Kan, 1994) and probably in most wild mammals, including rodents (Barnard \& Behnke, 1990). Associations may therefore be initiated in part by chance events combining with host behaviour, but their persistence (and therefore the likelihood of their detection) suggests that they may be maintained because the parasites concerned interact with one another, either directly or via the host.

\section{Synergistic (positive) interactions}

Nematodes may modify the internal environment within the host to make it more suitable for a second species, with the consequence that the second species stands a greater chance of survival in the presence of the first. This may arise because the first species weakens the host's defenses in order to facilitate its own survival, but thereby generates an opportunity for other species both to colonize the host and/or to survive longer than they otherwise would. This type of interaction was termed 'interactive protection from expulsion' by Mitchell (1979) and would be expected to lead to positive associations between species in wild host populations.

\section{Antagonistic (negative) interactions}

Parasites may also interact with each other antagonistically, leading to reduction in the abundance of the second species in animals harbouring the first species. Theoretically, antagonistic interactions between parasites may occur for a variety of reasons. Non-immunologically-mediated interactions may in- clude competition for attachment sites or for limited nutritional resources within the host, the action of toxic metabolic products from one species against another, and physical displacement as a consequence of a bulky biomass (e.g. adult cestodes, Haukisalmi \& Henttonen $1993 b)$.

Immunologically-mediated antagonism may arise through specific or non-specific cross immunity. If two parasite species share antigens, a specific immune response elicited by one may be effective against the second. A negative interaction may also follow when the host response to the first species generates a hostile environment in which the second species cannot survive adequately. This type of interaction was termed 'interactive intestinal expulsion’ by Mitchell (1979).

\section{SYNERGISTIC INTERACTIONS INVOLVING NEMATODES}

\section{Non-immunologically-mediated interactions}

There is little direct experimental evidence for nonimmunological synergistic interactions in the intestine between rodent nematodes of the type that have been reported in other host/parasite combinations (Holmes, 1973). Although nematode infections profoundly alter the intestinal environment this usually has no effect on other species present concurrently or is deleterious. For example, no evidence was found for altered growth rates or effects on fecundity during concurrent infections with Trichinella spiralis and Nippostrongylus brasiliensis in mice, other than in the phase when mice responded to either parasite with intestinal inflammation (Kennedy, 1980). In rats exposed concurrently to $N$. brasiliensis and Strongyloides ratti, the establishment of both nematodes was much the same as in single infection controls (Nawa \& Korenaga, 1983). Similarly, in three-way interactions between Hymenolepis diminuta, Moniliformis moniliformis and N. brasiliensis no evidence was found for synergistic interactions (Holland, 1987).

Species of nematodes found in concurrent infections often occur in different regions of the intestine, their distributions presumably determined by differences in the qualities of the niche occupied. This spatial separation may not favour non-immunological synergistic interactions and may in fact represent the consequences of antagonistic interactions (see below).

\section{Interactions mediated through the host's immune system}

Following a primary exposure the trichostrongyloid nematode Heligmosomoides polygyrus establishes long-lasting infections in mice. Experiments with the murine subspecies $H$. p. bakeri have shown that in most strains of laboratory mice infections last for 
8-10 months (Robinson et al. 1989). The parasite survives because it immunomodulates the intestinal environment, secreting immunomodulatory factors (IMF) that interfere with the T cell- and cytokinemediated regulation of the intestinal inflammatory response (Behnke, 1987); Monroy \& Enriquez, 1992); Telford et al. 1998). In particular, H. polygyrus infection impairs the mucosal mast cell response (Dehlawi, Wakelin \& Behnke 1987), although little is known about the molecular mechanisms involved. As might be expected, host protective immune responses against other species of intestinal nematodes, which depend on a functional mast cell response, are downregulated in concurrent infections, enabling the heterologous species to survive much longer than they otherwise would. For example, infections with Trichinella spiralis, which are normally terminated in 2-3 weeks, persist for more than 6 weeks when $H$. polygyrus is present (Behnke, Wakelin \& Wilson 1978). Similarly infections with Trichuris muris are also prolonged (Jenkins \& Behnke, 1977), enabling even moderately intense worm burdens to survive to patency (Behnke, Ali \& Jenkins 1984). This non-specific interactive protection from expulsion even extends to tapeworms such as Hymenolepis diminuta and H. citelli (Hopkins, 1980; Alghali, Hagan \& Robinson, 1985).

Experimental work involving concurrent infections with $H$. polygyrus and $T$. spiralis has shown that production of cytokines such as IL-9 and IL-10, which are required to elicit and sustain mucosal mastocytosis in response to infection with $T$. spiralis, is significantly inhibited in concurrent infections. The outcome is a less intense acute response, and a slower loss of T. spiralis (Behnke et al. 1993).

Trichuris muris is also believed to enhance its survival by host immunomodulation. During a primary infection $\mathrm{Th}_{2}$-mediated host-protective immunity operates primarily against larval stages, being considerably less effective against adult worms (Grencis, 1997). If the host response is delayed and the worms develop to the pre-adult and adult stages, chronic infections result. These stages are believed to secrete IMFs that polarize the host response towards $\mathrm{Th}_{1}$. Since such responses down-regulate $\mathrm{Th}_{2}$ activity, the parasite burden is then not expelled. This dependency of immunity against $T$. muris upon functional $\mathrm{Th}_{2}$ responses may well explain earlier observations that infections were prolonged in mice exposed to protozoan infections, where $\mathrm{Th}_{1}$ responses predominate (Phillips, Selby \& Wakelin, 1974; Phillips \& Wakelin, 1976). Similar data were obtained in concurrent infections between $T$. spiralis and Eimeria vermiformis (Rose, Wakelin \& Hesketh, 1994). Phillips \& Wakelin (1976) used concurrent infections involving Babesia microti, a species that is prevalent in wild rodent populations and therefore may exert an influence on their nematode infections. Effects upon the protozoan infection were not reported, but it is interesting to note that, more recently, in similar experiments involving $H$. polygyrus, it was demonstrated that the time-course of Babesia microti infections was not affected (Behnke, Sinski \& Wakelin, 1999).

The possibility that nematode-induced immune modulation influencing concurrent infections may be more widespread than so far studied experimentally is reinforced by data showing that a number of species release excretory/secretory factors capable of down-regulating host $\mathrm{T}$ cell proliferation (Allen \& MacDonald, 1998). It is also interesting to note that helminth-induced upregulation of $\mathrm{Th}_{2}$ responses has been proposed as a dominant factor in the pathogenesis of AIDS in Africa, such responses, and the corresponding downregulation of $\mathrm{Th}_{1}$ responses, making the host more susceptible to infection with HIV (Bentwich, Kalinkovich \& Weisman, 1995).

ANTAGONISTIC INTERACTIONS INVOLVING NEMATODES

\section{Non-immunologically-mediated interactions}

The niches occupied by adult nematodes in the intestine vary both longitudinally and radially. Longitudinally-distinct niches range from the oesophagus to the rectum, whilst radially-distinct niches include the lumen, the mucosal surface, the various layers of the mucosa itself and the serosa (Crompton, 1973). Niche selection begins at the establishment stage and is reflected in the choices made by incoming larvae (Holmes, 1961), 1973); Sommerville, 1963). Some have argued that the narrow location specificity of nematodes in the intestine is a reflection of past competitive interactions, leading to selective segregation and preferential selection of non-overlapping niches to minimize competition between species in order to achieve maximum fitness (Schad, 1963; Holmes, 1973). However, others have pointed out that since many niches in vertebrate hosts are unfilled (Price, 1980) niche segregation may be primarily driven by the need for parasites to aggregate for mating and reproduction (Rohde, 1979). Competitive interactions among helminth parasites in general have been thoroughly summarized by Christensen et al. (1987), and their longterm evolutionary consequences (i.e. extinction, and interactive or selective niche segregation) have been reviewed (Holmes, 1973), discussed (Rohde, 1979); Price, 1980) and modeled (Dobson, 1985).

\section{Interactions mediated through the host's immune system}

Non-specific inflammatory effector mechanisms. Intestinal inflammatory responses to infection with nematodes are controlled largely by Th lymphocytes through their release of cytokines that regulate the 
various effector arms (reviewed Behnke et al. 2000, Else \& Finkelman, 1999). Whilst there is general agreement that host-protective intestinal responses require functional $\mathrm{Th}_{2}$ cell activity, there is still controversy over what it is that actually causes worms to leave the host. One idea that has been current for many years is that the effectors released at the height of the acute response create an intestinal environment that is detrimental to worm survival. Early work using concurrent infections of $T$. spiralis and other parasites, suggested that the effector phase appeared to act non-specifically to bring about expulsion of heterologous species resident in the intestine at the time of the acute response to $T$. spiralis. Thus T. muris and Nippostrongylus brasiliensis were expelled prematurely when the host response to $T$. spiralis was maximal (Bruce \& Wakelin, 1977); Kennedy, 1980) and T. spiralis itself was lost prematurely when the response to $N$. brasiliensis was maximal (Kennedy, 1980). Protozoan parasites such as Giardia muris (Roberts-Thomson et al. 1976), Eimeria nieschulzi (Stewart, Reddington \& Hamilton, 1980) and E. pragensis (Rose et al. 1994) were also affected by inflammatory responses elicited by $T$. spiralis. Similarly, tapeworms such as $H$. diminuta and Rodentolepis nana were lost from $T$. spiralis-infected mice and rats (Behnke, Bland \& Wakelin, 1977); Christie, Wakelin \& Wilson, 1979); Ferretti et al. 1984). Rodentolepis (= Hymenolepis) microstoma suffered severe impairment to its growth but because of its relatively sheltered attachment position in the bile duct escaped expulsion from the intestine (Howard et al. 1978). Thus the picture which emerged from these studies was one in which an antigen-specific immune response elicited wide ranging and non-specific effector mechanisms, which removed other parasites out of the intestine at the time of, or immediately following, the acute response to the inducing species.

This picture was radically altered when Japanese workers published an elegant and informative set of experiments involving concurrent infections (reviewed Nawa et al. 1994). By exploiting nude (athymic) mice as a immunologically-inert host environment, they showed that injecting IL-4 (to induce a mastocytosis) into mice carrying both $N$. brasiliensis and Strongyloides ratti, resulted in the removal only of the latter species. This raised the concept of selectivity in the effectiveness of effector mechanisms, i.e. intestinal mucosal mastocytosis was essential for the elimination of $S$. ratti, but was a redundant effector in the case of $N$. brasiliensis. Instead, the latter succumbs to the infection-induced mucus response even though the products of activated mast cells are released during the course of infection (Nawa \& Korenaga, 1983). Later studies (Khan et al. 1993) showed that mastocytosis was also a key effector against Strongyloides venezuelensis, suggesting a genus-specific susceptibility.
Effect of non-specifically-elicited effectors on chronic nematode species. Experiments involving concurrent infections have been very informative in helping to understand how chronic nematode species survive in their hosts. When mice carrying low intensity infections with $H$. polygyrus (i.e. levels which minimize the immunomodulatory effects) were challenged with $T$. spiralis, the adult $H$. polygyrus were lost in proportion to the dose of $T$. spiralis administered (Behnke, Cabaj \& Wakelin 1992). Since it is known that there is a positive correlation between the dose of $T$. spiralis and the intensity of the mucosal response induced (Dehlawi \& Wakelin, 1995) this result indicates that $H$. polygyrus is susceptible in a dose-dependent manner to the nonspecific effectors of the mucosal response. Therefore, the survival strategy of $H$. polygyrus may depend more on preventing intestinal responses from occurring rather than on tolerating the hostile intestinal environment once elicited (Smith \& Bryant, 1986).

In contrast to $H$. polygyrus, hookworms were not eliminated during the course of a concurrent infection with $T$. spiralis (Behnke, Rose \& Little, 1994). The adults of neither Necator americanus nor Ancylostoma ceylanicum were lost when hamsters rejected superimposed infections with $T$. spiralis, indicating that in these species resilience to the nonspecific components of inflammatory responses are key features of the host-parasite relationship. How hookworms manage to survive in experimental model systems (e.g. hamsters) or in their canine and human hosts is still largely unknown, but current interest centres on hookworm products that alter the environment locally where the mouth-parts embed in the mucosa (Hotez \& Pritchard, 1995). The combination of firm, but not permanent attachment (hookworms move feeding stations at regular intervals, Kalkofen, 1970), bioactive chemicals and oxygen radical scavenging enzymes (Brophy \& Pritchard, 1992) may endow hookworms with sufficient resilience to survive acute responses to other parasites.

\section{Immunologically-specific interactions}

Cross immunity. There is very considerable antigenic cross-reactivity between parasitic nematodes, a fact that bedevils immunodiagnosis. Such cross-reactivity may also extend to antigens involved in hostprotective immune responses. There have been several records of cross-resistance between intestinal nematodes although an antigenic basis for the resistance has not always been demonstrated. One example where this has been shown concerns Trichinella spiralis and Trichuris muris, members of the same taxonomic group. Mice exposed to primary infection with $T$. spiralis or $T$. muris showed enhanced resistance to a subsequent challenge with the other species (Lee, Grencis \& Wakelin, 1982) 
and this resistance could be induced both by active immunization with an antigen preparation of each species and by adoptive transfer of immune lymphocytes.

Enhancement of $T h_{2}$-based responsiveness. Just as the polarization of host immunity towards $\mathrm{Th}_{1}$ responses may explain some examples of synergistic interactions (see above), the converse may provide a theoretical basis for antagonistic interactions. Experimental studies using T. muris, where the susceptibility of certain inbred mouse strains reflects the dominance of $\mathrm{Th}_{1}$ responses, have shown that susceptibility can be overridden by concurrent infections with parasites that induce strong specific $\mathrm{Th}_{2}$ responses. This has been demonstrated using $T$. spiralis and T. muris (Hermanek, Goyal \& Wakelin, 1994) and Schistosoma mansoni and T. muris (Curry et al. 1995). In both cases the $\mathrm{Th}$ changes were reflected in altered antibody isotype and cytokine profiles.

DO QUANTITATIVE INTERACTIONS INVOLVING NEMATODES EXIST IN NATURAL RODENT COMMUNITIES?

Evidence from the field-helminth communities in wild rodents

In host populations where total parasite species richness is high and where several core (dominant) species each show high prevalence, polyparasitism is likely to be common even in the absence of any synergistic interactions; indeed this is well recognized to be the case. Among randomly-associating helminth species, purely on grounds of probability, we would expect a preponderance of positive associations in component communities characterized by many common (prevalence $>90 \%$ ) species and negative associations when rare (prevalence $<10 \%$ ) species predominate (Lotz \& Font, 1994).

Kisielewska $(1970 b)$ was among the first to address the question of whether such co-occurrences include interactions between species. Her studies revealed that some species of nematodes showed antagonistic associations (Capillaria murissylvatici with Mastophorus muris, Heligmosomum halli $[$ now $=H$. mixtum, Tenora \& Meszaros, 1971)] with Heligmosomoides glareoli) whilst others showed synergistic associations e.g. H. mixtum with Syphacia obvelata [now =S. petrusewiczi, Tenora \& Meszaros, 1975)], S. petrusewiczi with $C$. murissylvatici, S. petrusewiczi with the cestode Catenotaenia pusilla (probably $C$. henttoneni, See Haukisalmi \& Tenora, 1993), and $H$. mixtum with $C$. henttoneni. However, Kisielewska $(1970 b)$ employed simple statistics in her analyses and re-examination of her results failed to substantiate the validity of these associations other than that involving H. mixtum and C. pusilla (Hobbs, 1980).
Employing considerably more powerful statistical tests, Haukisalmi \& Henttonen $(1993 a)$ came to the conclusion that significant associations of helminths were rare in Clethrionomys glareolus in Finland. Of the 12 pairs of helminths infecting their bank vole populations only 4 combinations $(H$. mixtum with Heligmosomoides glareoli, C. murissylvatici with $M$. muris, $H$. mixtum with Catenotaenia sp., and $H$. mixtum with the cestode Paranoplocephala gracilis), all positive, were identified in presence/absence data and only three showed significant quantitative associations (negative $-H$. mixtum with Catenotaenia sp., H. glareoli with $P$. gracilis and positive $-C$. murissylvatici with $M$. muris). Only two of these combinations interacted consistently (H. mixtum with Heligmosomoides glareoli, C. murissylvatici with $M$. muris), the other associations being weak and unpredictable with respect to the intrinsic and extrinsic factors that also influenced worm burdens.

Collectively these studies, and others, suggest that whilst helminths co-occur commonly in nature, associations (presence/absence data and quantitative) are rare and inconsistent when detected, often dependent on a particular season, site, or occurring only in specific years. Mostly, they are generated through factors other than interactions between the species concerned. Montgomery \& Montgomery (1990), who studied nine species of helminths in wood mice (Apodemus sylvaticus) in Northern Ireland, arrived at much the same conclusion.

Unequivocal demonstration that synergistic or antagonistic interactions between parasites occur in naturally infected animals is fraught with statistical and logistic difficulties. Co-occurrence, and moreover, associations of particular pairs of species, do not necessarily imply that interactions between them exist as species of parasites may aggregate independently in particular hosts for a variety of reasons. To give just two examples, parasite transmission stages may selectively infect hosts of a particular sex and age (e.g. because they forage more extensively, as males do in the breeding season) and infective stages may be aggregated in a particular microenvironment into which some hosts wander more often than others. Even quantitative associations (as reflected in statistically significant positive/negative correlations) may arise simply because hosts show patterns of behaviour that predispose them to infection with both of a pair of species of parasites.

\section{Taking the field systems into the laboratory}

The laboratory strain $H$. polygyrus bakeri is widely used as a model of chronic intestinal nematode infections (Monroy \& Enriquez, 1992). However, the fact that it was originally isolated from an abnormal host and has been passaged through various mouse strains for almost half a century (Behnke, Keymer \& Lewis, 1991), suggests that this 
parasite is probably now quite different from that found in wild animals in the field. In Europe, wood mice (Apodemus sylvaticus) carry a closely related species $H$. polygyrus polygyrus (Lewis 1968 a ; Montgomery \& Montgomery, 1988). This species has been isolated recently and experiments in wood mice have shown that infections last some 12 weeks or so, i.e. less than H. p. bakeri in laboratory mice (Gregory, Keymer \& Clarke, 1990) but considerably longer than species such as $T$. spiralis and $N$. brasiliensis. When this wild isolate was given to laboratory mice virtually no larvae survived the initial week of the tissue stage of infection (Quinnell, Behnke \& Keymer, 1991). Whilst, intuitively we might suppose H. p. polygyrus to employ a similar, albeit perhaps somewhat weaker, immunomodulatory strategy to H. p. bakeri, to our knowledge this has not been investigated.

In Europe, wild voles carry nematodes of the related genus Heligmosomum ('Tenora \& Meszaros, 1971; Meszaros, 1977); Tenora \& Stanek, 1995). In Poland, common voles, Microtus arvalis, show a high prevalence of infection with Heligmosomum costellatum (Bajer et al. unpublished). We have established both a breeding colony of the voles and cultures of the nematode to test hypotheses concerning immunomodulation as a survival strategy in this host-parasite combination. Preliminary data suggest that there are synergistic interactions between $H$. costellatum and the intestinal protozoan Cryptosporidium parvum, a species that infects domestic animals and is capable of causing severe enteritis in humans (James, 1997); Bednarska, Bajer \& Sinski, 1998). Common voles have proved to be competent reservoir hosts of $C$. parvum and individuals infected with adult $H$. costellatum have been found to excrete significantly more oocysts than worm free animals from day 17 post infection with $C$. parvum until the end of the observation period (day 42) (Bajer et al. 2000).

\section{Field tests of laboratory-generated hypotheses}

While earlier quantitative survey data on helminth parasites of wild wood mice and voles did not provide strong support for interactions between species, laboratory experiments with H.p. bakeri would suggest that synergistic interactions should be found between the related Heligmosominae (H. $p$. polygyrus, $H$. costellatum and $H$. mixtum) and other parasites. In a recent re-analysis of such data Behnke et al. (unpublished) found that whilst H. p. polygyrus was associated positively with other species in terms of categorical data (presence/absence), only one species, the cestode $C$. pusilla, showed a quantitative positive interaction, the number of $C$. pusilla increasing with increasing burdens of $H$. p. polygyrus. Perhaps surprisingly, after taking account of differences between sites, seasons and host intrinsic factors such as age and sex, there was little evidence of positive interactions between $H . p$. polygyrus and Syphacia stroma, two species that occupy a similar intestinal site and represent the dominant helminths of wood mice in the U.K.

\section{PRACTICAL IMPLICATIONS}

Understanding the extent to which nematodes predispose their rodent hosts to infection by heterologous species (whether nematodes or other parasites) is an important consideration, because wild rodents can act as reservoir hosts for parasites that can be transmitted to humans (zoonoses) and domestic animals. It is known that some parasites interfere with their host's defense mechanisms in order to facilitate their own survival and many of these species also show seasonal cycles of abundance in wild host populations. It might be expected, therefore, that such species could predispose hosts to co-infection by other parasites and other pathogens of potential medical significance at particular times of the year. If this were to be in the summer, coinciding with times when there is greater human contact with wildlife habitats, the potential for transmission would be greatly increased.

Some studies have shown that the prevalence and abundance of intestinal parasites in wood mice peaks in late autumn, winter and early spring (Kisielewska, 1970 a ; Montgomery \& Montgomery, 1988); AbuMadi et al. 1998). These seasons may be times of hardship for wild rodents which, although not normally regarded as commensal with humans, may move into human habitations for shelter. Wood mice, for example, often enter houses in the UK during the winter, at precisely the time when they carry the heaviest infections with $H$. polygyrus.

\section{WHERE FROM HERE?}

Perhaps the most interesting concept to emerge from this review in respect of interactions between nematodes and other parasites, is that there is a significant discrepancy between the findings from laboratory experiments and the observations gathered from wild rodents in the field. Whilst field workers have generally concluded that interactions between nematodes and other parasites play a minimal role in shaping the structures of helminth component communities, laboratory experiments have unequivocally demonstrated that under precisely controlled laboratory conditions such interactions do exist and can be quite drastic in their effects on particular species.

The strongest effects detected in laboratory experiments depend on positive or negative influences on the host's immune response by one of the interacting species. Intestinal immune responses are transient phenomena that occur over a period of days, or weeks at most, since sustaining regular and pro- 
longed bouts of intestinal inflammation is itself counter-productive for the host (Behnke et al. 2000). The failure to detect interactions among parasites of wild hosts reflects the difficulty of sampling sufficient animals with concurrent infections at a time when intestinal responses are taking place, and thus obtaining adequate data to generate a statistically significant result. Equally, parasite burden data derived from culled wild hosts, whether sampled at regular intervals or just in a restricted period, provide only snapshot information on current parasite burdens, some of which might or might not be influenced by past exposure to either homologous or heterologous infections. An additional factor is that low helminth burdens may not generate hostprotective immune responses (Behnke \& Wakelin, 1973 - or may do the opposite - Bancroft, Else \& Grencis, 1994), and the threshold for generating protective responses may be reached at different times, as worm burdens accumulate at different rates in individual hosts. The average life-span of wood mice and voles is only $2-3$ months during the summer season (Gliwicz, 1983); Flowerdew 1985) so that there may be a limited opportunity for slowly developing intestinal immunity to become manifest.

However, where one species interferes non-specifically with host immunocompetence and is longlived, as in the case of $H$. polygyrus, we might expect the probability of observing positive interactions to be higher. The lack of strong support for quantitative synergistic interactions between the heligmosomatids and other species (Haukisalmi \& Henttonen, $1993 b$ ) suggests that in nature, if they survive by immunomodulation, the effects of their evasive strategies are confined to the site of localization in the gut. In contrast to laboratory experiments, in which inocula of the order of 100-200 larvae have frequently been used (Jenkins \& Behnke, 1977); Behnke et al. 1978), parasite burdens of just 1-10 adult heligmosomatid worms may be insufficient to prevent the expression of immunity to other parasites (Pritchard \& Behnke, 1985), and hence too low to generate positive associations.

Most studies of helminths in wild rodents rely simply on presence/absence data or on total worm burdens (numbers of parasites), and few have been more ambitious in collecting data on individual parasite biomass, parasite fecundity or location (See Moore \& Simberloff, 1990) for helminth communities in quail). Since, in comparison to laboratory experiments, wild animals generally harbour low worm burdens, immune responses are likely to be milder in naturally infected hosts and in consequence their effects on heterologous species more subtle. Nevertheless, subtle effects on intestinal distribution have been observed. Haukisalmi \& Henttonen (1993b) noted that while common nematodes had some, but inconsistent, effects on the intestinal distribution of other helminths, rare parasites such as Capillaria sp. and the cestode P. gracilis, but also the more common Catenotaenia sp., were associated with minor but significant displacement of $H$. mixtum from its usual location.

As we hope to have demonstrated, the study of interactions between nematode and other parasites has far broader significance than in just rodent helminthology. Human polyparasitism is a major problem in regions where human GI nematodes are common and the exacerbation of morbidity and pathology in multiple species infections is an important consideration, both in human and veterinary medicine. Under infection regimes which were not too dissimilar to those animals might experience under conventional husbandry, it has been shown that intestinal nematodes of cattle can synergise to increase host susceptibility to lungworms (Kloosterman, Ploeger \& Frankena, 1990). In concurrent infections with Ostertagia leptoaspicularis and other bovine Ostertagia species establishment of both species was greater than when each was given alone (Al Saqur et al. 1984). Awareness of the specificity of protective responses, and in the light of rodent model systems, it was demonstrated that there was little cross immunity between common bovine GI nematodes (Adams, Anderson \& Windon, 1989) raising disappointment for those aiming to develop polyvalent wide-spectrum vaccines (Emery \& Wagland, 1991).

It is our view that there are still many exciting and relevant aspects of this topic that require further attention. The analysis of interactions between pairs of parasites in laboratory experiments has been a fruitful exercise and has not yet been exhausted. Each species of parasite is uniquely adapted to survival in its host and analysis of the diversity of their interactions has contributed to the development of ecological models of competitive interactions between species as well as shedding light on fundamental aspects of host protective immunity against parasites. It is vitally important to know whether or not laboratory-generated data on immune-based interactions can be extrapolated to natural populations of hosts, be these humans, domestic or wild animals. This information that in practice must come largely from field and laboratory work on nematodes of rodents, is necessary to provide a rational framework for informed decisions about research into and implementation of appropriate preventative control measures.

\section{ACKNOWLEDGEMENTS}

We are grateful to the British Council, UK and the State Committee for Scientific Research (KBN), Poland for financial support for our field studies (KBN Grants UM 855 and UM 930). We thank our colleagues, collaborators, postgraduate and undergraduate students who have contributed to, motivated and inspired our research activities in this field. 


\section{REFERENCES}

ABU-MADI, M. A., BEHNKE, J. M., LEWIS, J. W. \& GILBERT, F. S. (1998). Descriptive epidemiology of Heligmosomoides polygyrus in Apodemus sylvaticus from three contrasting habitats in south-east England. Fournal of Helminthology 72, 93-100.

ABU-MADI, M. A., BEHNKE, J. M., LEWIS, J. W. \& GILBERT, F. S. (2000). Seasonal and site specific variation in the component community structure of intestinal helminths in Apodemus sylvaticus from three contrasting habitats in south-east England. Fournal of Helminthology 74, 7-16.

ADAMS, D. B., ANDERSON, B. H. \& WINDON, R. G. (1989). Cross immunity between Haemonchus contortus and Trichostrongylus colubriformis in sheep. International Fournal for Parasitology 19, 717-722.

Alghali, S. T. O., Hagan, P. \& ROBINSON, M. (1985). Hymenolepis citelli (Cestoda) and Nematospiroides dubius (Nematoda): interspecific interactions in mice. Experimental Parasitology 60, 369-370.

ALlen, J. E. \& Macdonald, A. s. (1998). Profound suppression of cellular proliferation mediated by the secretions of nematodes. Parasite Immunology 20, 241-247.

AL SAQUR, I., ARMOUR, J., BAIRDEN, K., DUNN, A. M., JENNINGS, F. W. \& MURRAY, M. (1984). Experimental studies on the interaction between infections of Ostertagia leptospicularis and other bovine Ostertagia species. Zeitschrift für Parasitenkunde 70, 809-817. ASHFORD, R. W., CRAig, P. s. \& OPPENHEIMER, s. J. (1992). Polyparasitism on the Kenyan coast. 1. Prevalence and association between parasitic infections. Annals of Tropical Medicine and Parasitology 86, 671-679.

BAJER, A., BEHNKE, J. M., BEDNARSKa, M., KANICKA, M. \& SINSKI, E. (2000). The common vole (Microtus arvalis) as a competent host for Cryptosporidium parvum. (EMOP VIII, Poznan, 10-14 September, 2000.) Acta Parasitologica 45, 178.

BANCROFT, A. J., ELSE, K. J. \& GRENCIS, R. K. (1994). Lowlevel infection with Trichuris muris significantly affects the polarization of the CD4 response. European Fournal of Immunology 24, 3113-3118.

BARNARD, C. J. \& BeHNKe, J. M. (Eds) (1990). Parasitism and Host Behaviour. London, Taylor \& Francis.

Bednarska, M., BAJER, A. \& SINSKI, E. (1998). Calves as a potential reservoir of Cryptosporidium parvum and Giardia spp. Annals of Agricultural and Environmental Medicine 5, 135-138.

BEHNKE, J. м. (1987). Evasion of immunity by nematode parasites causing chronic infections. Advances in Parasitology 26, 1-71.

BeHNKe, J. M., ALI, N. M. H. \& JENKINS, S. N. (1984). Survival to patency of low level infections with Trichuris muris in mice concurrently infected with Nematospiroides dubius. Annals of Tropical Medicine and Parasitology 78, 509-517.

BehnKe, J. M., BLAND, P. W. \& WAKELIN, D. (1977). The effect of the expulsion phase of Trichinella spiralis on Hymenolepis diminuta infection in mice. Parasitology 75, 79-88.

Behnke, J. M., CABaJ, W. \& Wakelin, D. (1992). The susceptibility of adult Heligmosomoides polygyrus to intestinal inflammatory responses induced by heterologous infection. International Fournal for Parasitology 22, 75-86.

BeHNKe, J. M., KeYMer, A. E. \& LEWIS, J. W. (1991). Heligmosomoides polygyrus or Nematospiroides dubius? Parasitology Today 7, 177-179.

BeHNKe, J. M., LEWIS, J. W., MOHD ZAIN, S. N. \& GILBERT, F. s. (1999). Helminth infections in Apodemus sylvaticus in southern England: interactive effects of host age, sex and year on the prevalence and abundance of infections. Fournal of Helminthology 73, $31-44$.

Behnke, J. M., LOWE, A., MENGe, D., IRAQI, F. \& WAKElin, D. (2000). Mapping the genes for resistance to gastrointestinal nematodes. Acta Parasitologica 45, $1-13$.

BeHNKe, J. M., ROSE, R. \& LitTle, J. (1994). Resistance of the hookworms Ancylostoma ceylanicum and Necator americanus to intestinal inflammatory responses induced by heterologous infection. International Fournal for Parasitology 24, 425-431.

Behnke, J. M., Sinski, E. \& WAKelin, D. (1999). Primary infections with Babesia microti are not prolonged by concurrent Heligmosomoides polygyrus. Parasitology International 48, 183-187.

BEHNKe, J. M., WAHID, F. N., GRENCIS, R. K., ELSE, K. J., BENSMith, A. W. \& GOYAL, P. K. (1993). Immunological relationships during primary infection with Heligmosomoides polygyrus (Nematospiroides dubius): downregulation of specific cytokine secretion (IL-9 and IL-10) correlates with poor mastocytosis and chronic survival of adult worms. Parasite Immunology 15, 415-421.

BeHNKe, J. M. \& WAKELIN, D. (1973). The survival of Trichuris muris in wild populations of its natural hosts Parasitology 67, 157-164.

BeHNKE, J. M., WAKELIN, D. \& WILSON, M. M. (1978). Trichinella spiralis: Delayed rejection in mice concurently infected with Nematospiroides dubius. Experimental Parasitology 46, 121-130.

BeNTWiCh, z., KALINKOVICH, A. \& WEISMAN, z. (1995). Immune activation is a dominant factor in the pathogenesis of African AIDS. Immunology Today 16, 187-191.

BogGs, J. F., McMurRay, S. T., LESLie, D. M. JR., ENGLE, D. M. \& LOCHMiller, R. L. (1991). Influence of habitat modification on the community of gastrointestinal helminths of cotton rats. Fournal of Wildlife Diseases 27, 584-593.

BROPHY, P. M. \& PRITCHARD, D. I. (1992). Immunity to helminths: ready to tip the biochemical balance? Parasitology Today 8, 419-422.

BRUCE, R. G. \& WAKELIN, D. (1977). Immunological interaction between Trichinella spiralis and Trichuris muris in the intestine of the mouse. Parasitology 74, 163-173.

, A. A., ANDERSON, R. I., MACRAE, A. A. \& FAIN, A. (1978). Epidemiology of poly-parasitism. I. Occurrence, frequency and distribution of multiple infections in rural communities on Chad, Peru, Afganistan and Zaire. Tropical Medicine and Parasitology 29, 61-70.

BUNDY, D. A. P. \& Blumenthal, U. J. (1990). Human behaviour and the epidemiology of helminth 
infections: the role of behaviour in exposure to infection. In Parasitism and Host Behaviour (ed. Barnard, C. J. \& Behnke, J. M.), pp. 264-289.

London, Taylor \& Francis.

BUSH, A. o. \& HOLMES, J. C. (1986). Intestinal helminths of lesser scaup ducks: an interactive community. Canadian Fournal of Zoology 64, 142-152.

CHAN, L., BUNDY, D. A. P. \& KAN, S. P. (1994). Genetic relatedness as a determinant of predispostition to Ascaris lumbricoides and Trichuris trichiura infection. Parasitology 108, 77-80.

Christensen, N. O., NANSEN, P., FAgBemi, B. O. \& MONRAD, J. (1987). Heterologous antagonistic interactions between helminths and between helminths and protozoans in concurrent experimental infection of mammalian hosts. Parasitology Research 73, 387-410.

Christie, P. R., WAKelin, D. \& Wilson, M. M. (1979). The effect of the expulsion phase of Trichinella spiralis on Hymenolepis diminuta infection in rats. Parasitology 78, 323-330.

Chunge, R. N., KARUMBa, N., OUMA, J. H., ThiOngO, F. W., STURRock, R. F. \& BUTTERWORTH, A. E. (1995).

Polyparasitism in two rural communities with endemic Schistosoma mansoni infection in Machakos District, Kenya. Fournal of Tropical Medicine and Hygiene 98, 440-444.

CROMPton, D. W. T. (1973). Sites occupied by some parasitic helminths in the alimentary tract of vertebrates. Biological Reviews 48, 27-83.

CURRY, A. J., ELSE, K. J., JONES, F., BANCROFT, A., GRENCIS, R. K. \& DUNNE, D. W. (1995). Evidence that cytokinemediated immune interactions induced by Schistosoma mansoni alter disease outcome in mice concurrently infected with Trichuris muris. Fournal of Experimental Medicine 181, 769-774.

DEHLAWI, M. S. \& WAKELIN, D. (1995). Dose dependency of mucosal mast cell responses in mice infected with Trichinella spiralis. Research and Reviews in Parasitology 55, 21-24.

Dehlawi, M. S., WAKELIN, D. \& BeHNKe, J. M. (1987). Suppression of mucosal mastocytosis by infection with the intestinal nematode Nematospiroides dubius.

Parasite Immunology 9, 187-194.

Dobson, A. P. (1985). The population dynamics of competition between parasites. Parasitology 91, 317-347.

ELSE, K. J. \& FINKELMAN, F. D. (1999). Intestinal nematode parasites, cytokines and effector mechanisms. International Fournal for Parasitology 28, 1145-1158.

EMERY, D. L. \& WAGLAND, B. M. (1991). Vaccines against gastrointestinal nematode parasites of ruminants. Parasitology Today 7, 347-349.

Ferretti, G., Gabriele, F., PAlmas, C. \& WAKelin, D. (1984). Interactions between Trichinella spiralis and Hymenolepis nana in the intestine of the mouse. International Fournal for Parasitology 14, 29-33.

FLOWERDEW, J. R. (1985). The population dynamics of wood mice and yellow-necked mice. In The Ecology of Woodland Rodents, Bank Voles and Wood Mice (eds. Flowerdew, J. R., Gurnell, J. \& Gipps, J. H. W.), pp. 315-338 Symposia of the Zoological Society of London 55.
GLiwicz, J. (1983). Survival and life span. In Ecology Of The Bank Vole (ed. Petrusewicz, K) Acta Theriologica 28 (suppl 1), 161-172.

GREGORY, R. D., KEYMER, A. E. \& CLARKE, J. R. (1990).

Genetics, sex and exposure: the ecology of Heligmosomoides polygyrus (Nematoda) in the wood mouse. Fournal of Animal Ecology 59, 363-378.

GRENCIS, R. K. (1997). Th2-mediated host protective immunity in intestinal nematode infections. Philosophical Transactions of the Royal Society of London B 352, 1377-1384.

HAUkisalmi, v. \& HeNTTONEN, H. (1993 $a$ ). Coexistence in helminths of the bank vole Clethrionomys glareolus. I. Patterns of co-occurrence. Fournal of Animal Ecology 62, 221-229.

HaUkisalmi, v. \& HentTonen, H. (1993 b). Coexistence in helminths of the bank vole Clethrionomys glareolus. II. Intestinal distribution and interspecific interactions. Fournal of Animal Ecology 62, 230-238.

haukisalmi, v., henttonen, H. \& Tenora, F. (1988). Population dynamics of common and rare helminths in cyclic vole populations. Fournal of Animal Ecology 57, 807-825.

haukisalmi, v. \& Tenora, F. (1993). Catenotaenia henttoneni sp. n. (Cestoda: Catenotaeniidae), a parasite of voles Clethrionomys glareolus and C. rutilus (Rodentia). Folia Parasitologica 40, 29-33.

HeRmaneK, J., GOYAL, P. K. \& WAKelin, D. (1994). Lymphocyte, antibody and cytokine responses during concurrent infections between helminths that selectively promote T-helper-1 or T-helper-2 activity. Parasite Immunology 16, 111-117.

новBS, R. P. (1980). Interspecific interactions among gastrointestinal helminths in pikas of North America. American Midland Naturalist 103, 15-25.

HOLLAND, C. (1987). Interspecific effects between Moniliformis (Acanthocephala), Hymenolepis (Cestoda) and Nippostrongylus (Nematoda) in the laboratory rat. Parasitology 94, 567-581.

HOLMES, J. C. (1961). Effects of concurrent infections on Hymenolepis diminuta (Cestoda) and Moniliformis dubius (Acantheocephala). I. General effects and comparison with crowding. Fournal of Parasitology 47, 209-216.

Holmes, J. C. (1973). Site selection by parasitic helminths: interspecific interactions, site segregation and their importance to the development of the helminth communities. Canadian Fournal of Zoology 51, 333-347.

HOPKINs, c. A. (1980). Immunity and Hymenolepis diminuta. In Biology of the Tapeworm Hymenolepis diminuta (ed. Arai, H. P.), pp. 551-614. New York, Academic Press.

HOTEZ, P. J. \& PRITChARD, D. I. (1995). Hookworm infection. Scientific American June 1995, 42-48.

HOWARD, R. J., Christie, D., WAKELIN, D., Wilson, M. M. \& BEHNKe, J. M. (1978). The effect of concurrent infection with Trichinella spiralis on Hymenolepis microstoma in mice. Parasitology 77, 273-279.

JAMES, s. L. (1997). Emerging parasitic infections. FEMS Immunology and Medical Microbiology 18, 313-317.

JENKINS, s. N. \& BEHNKE, J. M. (1977). Impairment of primary expulsion of Trichuris muris in mice 
concurrently infected with Nematospiroides dubius. Parasitology 75, 71-78.

Kalkofen, U. P. (1970). Attachment and feeding behaviour of Ancylostoma caninum. Zeitschirft für Parasitenkunde 33, 339-354.

KENNEDY, C. R, BUSH, A. O. \& AHO, J. M. (1986). Patterns in helminth communities: why are birds and fish different? Parasitology 93, 205-215.

KENNEDY, M. W. (1980). Immunologically mediated, nonspecific interactions between the intestinal phases of Trichinella spiralis and Nippostrongylus brasiliensis in the mouse. Parasitology 80, 61-72.

Keusch, G. T. \& Migasena, P. (1982). Biological implications of polyparasitism. Reviews of Infectious Diseases 4, 880-882.

KHAN, A. I., HORII, Y., TIURUA, R., SATO, Y. \& NAWA, Y. (1993). Mucosal mast cells and the expulsive mechanisms of mice against Strongyloides venezuelensis. International Fournal for Parasitology 23, 551-555.

KISIELEWSKA, K. $(1970 a)$. Ecological organization of intestinal helminth groupings in Clethrionomys glareolus (Schreb.) (Rodentia). 1. Structure and seasonal dynamics of helminth groupings in a host population in the Białowieża National Park. Acta Parasitologica Polonica 18, 121-147.

KISIELEWSKA, K. (1970 b). Ecological organization of intestinal helminth groupings in Clethrionomys glareolus (Schreb.) (Rodentia). V. Some questions concerning helminth groupings in the host individuals. Acta Parasitologica Polonica 17, 197-208.

Kloosterman, A., Ploeger, H. W. \& FRANkena, K. (1990). Increased establishment of lungworms after exposure to a combined infection of Ostertagia ostertagi and Cooperia oncophora. Veterinary Parasitology 36, 117-122.

KVAlsvig, J. D. (1988). The effects of parasitic infection on cognitive performance. Parasitology Today 4, 206-208.

LEE, T. D. G., GRENCIS, R. K. \& WAKELIN, D. (1982). Specific cross-immunity between Trichinella spiralis and Trichuris muris: immunization with heterologous infections and antigens and transfer of immunity with heterologous immune mesenteric lymph node cells. Parasitology 84, 381-389.

LEWIS, J. W. (1968 $a$ ). Studies on the helminth parasites of the long-tailed field mouse, Apodemus sylvaticus sylvaticus from Wales. Fournal of Zoology, London 154, 287-312.

LEWIS, J. W. (1968 $b$ ). Studies on the helminth parasites of voles and shrews from Wales. Fournal of Zoology, London 154, 313-331.

LOTZ, J. M. \& FONT, W. F. (1994). Excess positive associations in communities of intestinal helminths of bats: a refined null hypothesis and a test of the facilitation hypothesis. Fournal of Parasitology $\mathbf{8 0}$, 398-413.

MARTin, J. L. \& HUfFMAn, D. G. (1980). An analysis of the community and population dynamics of the helminths of Sigmodon hispidus (Rodentia: Criceditae) from three central Texas vegetational regions. Proceedings of the Helminthological Society of Washington 47, 247-255. meszaros, F. (1977). Parasitic nematodes of Microtus arvalis (Rodentia) in Hungary. Parasitologica Hungarica 10, 67-83.

Mitchell, G. F. (1979). Effector cells, molecules and mechanisms in host-protective immunity to parasites. Immunology 38, 209-223.

MOLlHagEN, T. (1978). Habitat influence on helminth parasitism of the cotton rat in western Texas, with remarks on some of the parasites. The Southwestern Naturalist 23, 401-408.

MONROY, F. G. \& ENRIQUeZ, F. J. (1992). Heligmosomoides polygyrus: a model for chronic gastrointestinal helminthiasis. Parasitology Today 8, 49-54.

MONTGOMERY, S. S. J. \& MONTGOMERY, W. I. (1988). Cyclic and non-cyclic dynamics in populations of the helminth parasites of wood mice Apodemus sylvaticus. Fournal of Helminthology 62, 78-90.

MONTGOMERY, s. s. J. \& MONTGOMERY, W. I. (1989). Spatial and temporal variation in the infracommunity structure of helminths of Apodemus sylvaticus (Rodentia: Muridae). Parasitology 98, 145-150.

MONTGOMery, s. S. J. \& MONTGOMERY, W. I. (1990). Structure, stability and species interactions in helminth communities of wood mice, Apodemus sylvaticus. International Fournal for Parasitology 20, $225-242$.

MOORE, J. \& SIMBERLofF, D. (1990). Gastrointestinal helminth communities of bobwhite quail. Ecology 71, 344-359.

NAWA, Y., ISHIKAWA, N., TSUChIYA, K., HORII, Y., ABE, T., KHAN, A. I., BING-SHI, ITOH, H., IDE, H. \& UCHIYAMA, F. (1994). Selective effector mechanisms for the expulsion of intestinal helminths. Parasite Immunology 16, 333-338

NAWA, Y. \& KORENAGA, M. (1983). Mast and goblet cell responses in the small intestine of rats concurrently infected with Nippostrongylus brasiliensis and Strongyloides ratti. Fournal of Parasitology 69, 1168-1170.

PENCE, D. B., CRUM, J. M. \& CONTI, J. A. (1983). Ecological analyses of helminth populations in the black bear, Ursus americanus, from North America. Fournal of Parasitology 69, 933-950.

PETNEy, T. N. \& ANDREWs, R. H. (1998). Multiparasite communities in animals and humans: frequency, structure and pathogenic significance. International Fournal for Parasitology 28, 377-393.

Phillips, R. S., SElby, G. R. \& WAKELIN, D. (1974). The effect of Plasmodium berghei and Trypanosoma brucei infections on the immune expulsion of the nematode Trichuris muris from mice. International fournal for Parasitology 4, 409-415.

PHILlips, R. S. \& WAKELIN, D. (1976). Trichuris muris: effect of concurrent infections with rodent piroplasms on immune expulsion from mice. Experimental Parasitology 39, 95-100.

PRICE, P. W. (1980). Evolutionary biology of parasites. Monographs in Population Biology 15, Princeton University Press, Princeton, New Jersey, USA.

PRITCHARD, D. I. \& BEHNKE, J. M. (1985). The suppression of homologous immunity by soluble adult antigens of Nematospiroides dubius. Fournal of Helminthology 59, 251-256. 
QUINNELL, R. J., BEHNKE, J. M. \& KEYMER, A. E. (1991). Host specificity of and cross-immunity between two strains of Heligmosomoides polygyrus. Parasitology 102, 419-427.

ROBERTS-THOMSON, I. C., GROVE, D. I., STEVENS, D. P. \& WARREN, K. S. (1976). Suppression of giardiasis during the intestinal phase of trichinosis in the mouse. Gut 17, 953-958.

ROBINSON, M., WAHID, F. N., BEHNKE, J. M. \& GILBERT, F. S. (1989). Immunological relationships during primary infection with Heligmosomoides polygyrus (Nematospiroides dubius): dose-dependent expulsion of adult worms. Parasitology 98, 115-124.

ROHDE, K. (1979). A critical evaluation of intrinsic and extrinsic factors responsible for restriction in parasites. The American Naturalist 114, 648-671.

Rose, M. E., WAKELIN, D. \& HESKETH, P. (1994).

Interactions between infections with Eimeria spp. and Trichinella spiralis in inbred mice. Parasitology 108, 69-75.

SCHAD, G. A. (1963). Niche diversification in a parasitic species flock. Nature, London 198, $404-406$.

SMith, N. C. \& BRYANT, c. (1986). The role of host generated free radicals in helminth infections: Nippostrongylus brasiliensis and Nematospiroides dubius compared. International Fournal for Parasitology 16, 617-622.

SOMMERVILle, R. I. (1963). Distribution of some parasitic nematodes in the alimentary tract of sheep, cattle and rabbits. Fournal of Parasitology 49, 593-599.

STEWART, G. L., REDDington, J. J. \& HAMilton, A. M. (1980). Eimeria nieschulzi and Trichinella spiralis in the rat. Experimental Parasitology 50, 115-122.

TELFORD, G., WHEELER, D. J., APPLEBY, P., BOWEN, J. G. \& PRITCHARD, D. I. (1998). Heligmosomoides polygyrus immunomodulatory factor (IMF) targets Tlymphocytes. Parasite Immunology 20, 601-611.

TENora, F. \& Meszaros, F. (1971). Nematodes of the genus Heligmosomum Railliet et Henry, 1909), sensu Durette-Desset, 1968), parasitizing rodents in Europe. Acta Zoologica Academiae Scientiarum Hungaricae 17, 397-407.

TENora, F. \& MEszaros, F. (1975). Nematodes of the genus Syphacia, Seurat, 1916) (Nematoda)-parasites of rodents (Rodentia) in Czechoslovakia and Hungary. Acta Universitatis Agriculturae, Brno 23, 537-554.

TENORA, F. \& STANEK, M. (1995). Changes of the helminthofauna in several muridae and Arvicolidae at Lednice in Moravia. II. Ecology. Acta Universitatis Agriculturae et Silviculturae Mendelianae Brunensis 43, 57-65.

WAID, D. D., PENCE, D. B. \& WARREN, R. J. (1985). Effects of season and physical condition on the gastrointestinal community of white-tailed deer from Texas Edwards Plateau. Fournal of Wildlife Diseases 21, 264-273. 